Volume 6

Number 2 Unsolicited Issue

Article 1

December 2020

\title{
The LIHTC Program, Racially/Ethnically Concentrated Areas of Poverty, and High-Opportunity Neighborhoods
}

Kirk McClure

Anne R. Williamson

Hye-Sung Han

Brandon Weiss

American University Faculty Account, weiss@wcl.american.edu

Follow this and additional works at: https://scholarship.law.tamu.edu/journal-of-property-law

Part of the Property Law and Real Estate Commons

\section{Recommended Citation}

Kirk McClure, Anne R. Williamson, Hye-Sung Han \& Brandon Weiss, The LIHTC Program, Racially/ Ethnically Concentrated Areas of Poverty, and High-Opportunity Neighborhoods, 6 Tex. A\&M J. Prop. L. 89 (2020).

Available at: https://doi.org/10.37419/JPL.V6.I2.1

This Article is brought to you for free and open access by Texas A\&M Law Scholarship. It has been accepted for inclusion in Texas A\&M Journal of Property Law by an authorized editor of Texas A\&M Law Scholarship. For more information, please contact aretteen@law.tamu.edu. 


\title{
The LiHTC Program, Racially/Ethnically Concentrated Areas of Poverty, and High-Opportunity Neighborhoods
}

\author{
By: Kirk McClure, Ph.D., Anne R. Williamson, Ph.D., \\ Hye-Sung Han, Ph.D., and Brandon M. Weiss $\dagger$
}

\begin{abstract}
The Low-Income Housing Tax Credit ("LIHTC") program remains the nation's largest affordable housing production program. LIHTC units are under-represented in the neighborhoods that both promote movement to highopportunity neighborhoods and affirmatively further fair housing. State and local officials should play an active role in guiding site selection decisions and ensuring that LIHTC developments are located in a manner that affirmatively furthers fair housing. Planners can use newly available data discussed herein to identify high-opportunity tracts.
\end{abstract}

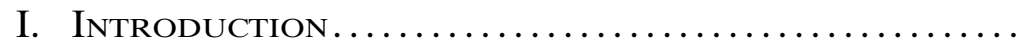

II. Prior Research on the Location of LiHTC Properties in Promoting Neighborhood

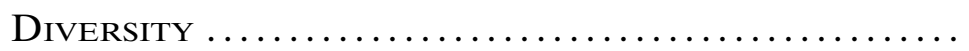

III. Distribution of Poverty Within Neighborhoods Where LiHTC Properties Are Located...........

IV. Racial Composition of Neighborhoods Where LiHTC Properties Are Located ...................

V. Socio-Economic Characteristics of LIHTC

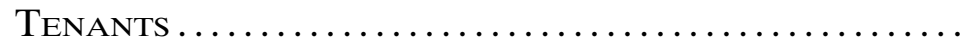

VI. Recent Legal Developments Relevant to LiHTC Siting Decisions ............................... 96

VII. Data AND Analysis ........................... 98

A. Data and Methods ......................... 98

B. Analysis............................... 98

1. How Many R/E CAPs Exist and What Share of the Population and Rental Housing Stock Do They Contain? .........................

2. How Many LIHTC Units Are There By Year Placed in Service? What Share Left the Program? ...............................

DOI: https://doi.org/10.37419/JPL.V6.I2.1

$\dagger$ Kirk McClure, Ph.D., Professor, Urban Planning Program, School of Public Affairs and Administration, University of Kansas; Anne R. Williamson, Ph.D., Victor and Caroline Schutte/Missouri Professor of Urban Affairs, and Director, L.P. Cookingham Institute of Urban Affairs, Department of Public Affairs, Henry W. Bloch School of Management, University of Missouri-Kansas City; Hye-Sung Han, Ph.D., Assistant Professor of Urban Administration, Department of Public Affairs, Henry W. Bloch School of Management, University of Missouri-Kansas City; Brandon M. Weiss, Associate Professor of Law, School of Law, University of Missouri-Kansas City. 
3. To What Extent Have LIHTC Developments

Located in R/E CAPs? ................... 100

4. Where Are LIHTC Units Located By R/E

CAPs and Racial/Ethnic Composition of

Tracts? ............................. 101

5. What Can Be Done? What Should Be Done?.. 104

6. What Resources Are Available to Planners? ... 108

VIII. Conclusions and Policy Implications ............ 109

\section{INTRODUCTION}

The Low-Income Housing Tax Credit ("LIHTC") program allocates federal tax credits annually to states, which in turn award the tax credits to developers who compete for the credits. States publish Qualified Allocation Plans ("QAPs") to guide developers in these competitions. The QAPs provide guidance to developers on the states' priorities in terms of which development proposals should win the credits. Once awarded, developers transfer the tax credits to investors who become part of the development's ownership. ${ }^{1}$ The investors use the credits to reduce federal tax liability, and if the investor is a bank, gain Community Reinvestment Act ("CRA") points. ${ }^{2}$ The proceeds from the transfer of the credits usually cover a large part of the development costs. The tax credits are provided for ten years in exchange for the development remaining in low-income occupancy for at least fifteen years, and often the commitment is for a much longer period of time. Rents are set at a level affordable to a household whose income is at $60 \%$ (or sometimes $50 \%$ ) of the metropolitan area median family income. ${ }^{3}$ In its history, the program has generated approximately 2.6 million units of which 2.4 million units remain in the program.

Developers drive the program by preparing the development proposals and selecting the locations for the developments. This research examines how state and local officials, particularly in concert with planners able to access newly available data, can influence developers' decisions through state QAPs. Specifically, this research asks:

1. Do the locations promote poverty deconcentration?

2. Do the locations affirmatively further fair housing?

3. Do the locations improve access to opportunity?

1. Ed Gramlich, Low Income Housing Tax Credits, Nat'L Low Income Hous. CoAL., 5-30 to 5-31, https://nlihc.org/sites/default/files/AG-2017/2017AG_Ch05-S09_ Low-Income-Housing-Tax-Credits_LITEC.pdf [https://perma.cc/UHT6-P2Q3].

2. See Cassandra Jones Havard, The Community Reinvestment Act, Banks, and the Low Income Housing Tax Credit, 26 J. Affordable Housing \& Community Dev. L. 415, 417-18 (2017).

3. Gramlich, supra note 1 , at 5-31 to 5-32. 


\section{Prior Research on the Location of LiHTC Properties in Promoting Neighborhood Diversity}

The lack of high-quality affordable housing outside high-poverty areas reinforces racial and economic segregation. Studies show that government policies, like the siting of public housing in already poor, inner-city minority neighborhoods and leasing them to poor tenants, have been particularly responsible for fostering segregation. ${ }^{4}$ While some subsidized housing programs aim to provide affordable housing in higher-opportunity neighborhoods, scholars argue that traditional public housing programs are concentrated in disadvantaged neighborhoods in terms of income level, minority population, and poverty rate. ${ }^{5}$ Residents in concentrated and often isolated pockets of poverty have limited access to jobs and high-quality health care, and they are exposed to a poor quality of education and higher crime rates. ${ }^{6}$

\section{Distribution of Poverty Within Neighborhoods Where LiHTC Properties Are Located}

State housing finance agencies develop Qualified Allocation Plans ("QAPs") that define policies and procedures for allocating housing tax credits to affordable rental housing developments that address state housing needs and priorities. This program feature should allow each state to provide an equitable distribution of affordable housing that encourages the deconcentration of poverty and promotes access to high-opportunity neighborhoods. However, studies have shown that the LIHTC program has been unsuccessful in producing a deconcentration of poverty. ${ }^{7}$

Sandra J. Newman and Ann B. Schnare, in their paper examining the influence of six housing programs on neighborhood quality on a national scale, found that LIHTC projects are concentrated in lowincome neighborhoods and their impact on improving neighborhood

4. See generally Lance Freeman, Siting Affordable Housing: Location and Neighborhood Trends of Low Income Housing Tax Credit Developments in the 1990s, CTR. on URb. ANd Metropolitan Pol'y 1 (Mar. 2004); Myron Orfield, Racial Integration and Community Revitalization: Applying the Fair Housing Act to the Low Income Housing Tax Credit, 58 V AND. L. Rev. 1747 (Nov. 2005); William A. Rohe \& Lance Freeman, Assisted Housing and Residential Segregation: The Role of Race and Ethnicity in the Siting of Assisted Housing Developments, 67 J. Am. Plan. Ass'N 279 (2001).

5. See, e.g., Ayoung Woo \& Young-Jae Kim, Spatial Location of Place-Based Subsidized Households and Uneven Geography of Opportunities: Case of Austin, Texas in the U.S., Community Dev. 8-10 (2015).

6. Gregory D. Squires \& Charis E. Kubrin, Privileged Places: Race, Uneven Development and the Geography of Opportunity in Urban America, 42 URB. STUd. 47, 52-54 (Jan. 2004).

7. See, e.g., Shannon Van Zandt \& Pratik C. Mhatre, Growing Pains: Perpetuating Inequality Through the Production of Low-Income Housing in the Dallas/Fort Worth Metroplex, 30 Urb. GeOgraphy 490, 501, 504-505 (2009). 
quality for residents is neutral at best. ${ }^{8}$ A study by Jean L. Cummings and Denise DiPasquale on the first ten years of the LIHTC program in major metropolitan areas supports Newman and Schnare's conclusion. ${ }^{9}$ They found that LIHTC developments are much more likely to provide better quality housing in low-income neighborhoods than to provide affordable housing in higher-income neighborhoods. ${ }^{10}$ Kirk McClure analyzed the neighborhood poverty concentration of different federal housing programs in 2002 and found that these programs do not lead to greater income integration. ${ }^{11}$ More recently, Casey Dawkins examined the extent of clustering in LIHTC projects placed in service between 1987 and 2006 within the ten largest metropolitan areas and found that LIHTC properties were more clustered than other housing units and tended to be located in more densely-developed central city locations that have higher poverty rates. ${ }^{12}$

LIHTC properties are more likely to be located in areas of less poverty when located in suburbs instead of inner cities. Lance Freeman found that LIHTC units are located in neighborhoods where the incidence of poverty is higher than that found for metropolitan neighborhoods generally. ${ }^{13}$ However, those LIHTC units that are located in the suburbs are found in neighborhoods with higher median incomes and lower levels of poverty than central city locations. ${ }^{14}$ McClure examined the spatial distribution of LIHTC developments placed in service from 1987 through 2002 and found that the LIHTC program placed an increasing share of its units in suburban and low-poverty census tracts as the price of tax credits increased over time..$^{15}$ In another study, Jill Khadduri, Larry Buron, and Carissa Climaco examined the location of LIHTC units placed in service between 1995 and 2003 in metropolitan areas with populations greater than $250,000 .{ }^{16}$ They found that, while about $22 \%$ of LIHTC family units

8. Sandra J. Newman \& Ann B. Schnare, “. . .And a Suitable Living Environment": The Failure of Housing Programs to Deliver on Neighborhood Quality, 8 Housing Pol'y Debate 703, 724-26, 728 (1997).

9. See Jean L. Cummings \& Denise DiPasquale, The Low-Income Housing Tax Credit: An Analysis of the First Ten Years, 10 Housing PoL'y Debate 251, 272 (1999).

10. Id. at $268-72$.

11. Kirk McClure, Deconcentrating Poverty with Housing Programs, 74 J. Ам. Plan. Ass'n 90, 93-95 (2007).

12. Casey Dawkins, The Spatial Pattern of Low Income Housing Tax Credit Properties: Implications for Fair Housing and Poverty Deconcentration Policies, 79 J. Am. Plan. Ass'n 222, 226-29 (Summer 2013).

13. Id.

14. Id.

15. Kirk McClure, The Low-Income Housing Tax Credit Program Goes Mainstream and Moves to the Suburbs, 17 Housing Pol'y Debate 419 (2006).

16. Jill Khadduri et al., Abt Assocs. Inc., Are States Using the Low Income Housing Tax Credit to Enable Families with Children to Live in Low Poverty and Racially Integrated Neighborhoods? 4 (2006), https://prrac.org/ pdf/LIHTC_report_2006.pdf [https://perma.cc/L9DR-UFRA]. 
are located in low-poverty neighborhoods, about $65 \%$ of LIHTC family units in low and moderate-poverty locations are in the suburbs. ${ }^{17}$ The authors found that the number of LIHTC family units in low and moderate-poverty tracts increased steadily between 1995 and 2001 and stated that the increased value of the tax credit for developers and state policy choices, such as those contained in QAPs, are possible reasons for the upward trend. ${ }^{18}$ More recently, McClure and Bonnie Johnson examined whether assisted rental housing increases LIHTC presence in high-opportunity neighborhoods. They found that the LIHTC program is entering into high-opportunity neighborhoods, especially in the suburbs. The authors posit that developers are beginning to find ways to surmount the barriers preventing entry into the suburbs, although more needs to be done. ${ }^{19}$

Other researchers found similar results but expressed caution regarding the interpretation of increasing access to high-opportunity suburban neighborhoods. Shannon Van Zandt and Pratik C. Mhatre, for example, found that although LIHTC developments are penetrating the suburbs, they are not expanding opportunities for these households. Just under half of LIHTC units are found in highly clustered areas characterized by high poverty rates, minority concentrations, poor educational opportunities, and rampant crime. The remaining units are dispersed in areas with moderate conditions. ${ }^{20}$

\section{Racial Composition of Neighborhoods Where LiHTC Properties Are Located}

Several studies have examined the racial composition of tracts where LIHTC developments are sited. The studies also examined the influence these properties have on furthering or limiting racial segregation in the communities where they are located. The studies suggest that the majority of LIHTC properties have been developed in areas of relatively high minority concentration.

Khadduri, Buron, and Climaco examined the location of LIHTC units placed in service between 1995 and 2003 in metropolitan areas with populations greater than 250,000 . They found that only a few states place more than $50 \%$ of their LIHTC housing in census tracts with minority population rates below half the rate for the metropoli$\tan$ area. ${ }^{21}$ The authors posit that providing less racially isolated housing opportunities does not appear to be a priority for many states. ${ }^{22}$ William M. Rohe and Lance Freeman, in their study examining the

17. Id. at 7,9 .

18. Id. at 8 .

19. Kirk McClure \& Bonnie Johnson, Housing Programs Fail to Deliver on Neighborhood Quality, Reexamined, 25 Housing PoL'y DeBATE 463, 491-93 (2014).

20. Van Zandt \& Mhatre, supra note 7, at 490.

21. KHADDURI ET AL., supra note 16, at 17-18.

22. Id. at 22 . 
role of race and ethnicity in the siting of assisted housing developments in the 1980s, found that the percentage of black residents in a neighborhood was a relatively strong predictor of the placement of LIHTC developments. ${ }^{23}$ However, the percentage did not influence the placement of other types of assisted housing. ${ }^{24}$ In an analysis of the location and neighborhood characteristics of housing developments funded by the federal LIHTC program in the 1990s, Freeman found that blacks are overrepresented in neighborhoods with LIHTC units. While blacks make up $15 \%$ of metropolitan residents generally, they account for $26 \%$ of the population in LIHTC neighborhoods. ${ }^{25}$ The author concluded that the siting patterns of LIHTC units reflect overall patterns in the residential segregation of blacks, as well as their lower socioeconomic status. ${ }^{26}$ Dawkins examined the extent of clustering in LIHTC projects within the ten largest U.S. metropolitan areas in 2000 and found that clustered LIHTC properties had a tendency to be located in more densely developed central-city locations that had higher poverty rates and higher minority concentrations. ${ }^{27}$ In an exploratory study of 39 properties in five metropolitan areas in the 1990s, Larry Buron, Sandra Nolden, Kathleen Heintz, and Julie Stewart found that LIHTC neighborhoods had a tendency to have a high proportion of minority residents. Roughly half of the neighborhoods had predominately (greater than $80 \%$ ) minority residents and only $12 \%$ had predominately white residents. ${ }^{28}$ Using a detailed database on 2,554 LIHTC projects established in the first ten years of the program, Cummings and DiPasquale found that a "significant portion of the projects in the sample [were] located in racially homogeneous neighborhoods." 29

\section{Socio-Economic Characteristics of LiHTC Tenants}

The intention of the LIHTC program may have been to promote broader economic diversity among LIHTC residents by incorporating minimum requirements on mixing income-restricted units with market-rate units. ${ }^{30}$ The program gives preference to developments that set aside affordable units. However, there are very few empirical stud-

23. Rohe \& Freeman, supra note 4, at 284.

24. Id. at 287.

25. Freeman, supra note 4 , at 7.

26. Id. at 8 .

27. Dawkins, supra note 12 , at 229-231.

28. Larry Buron et al., Abt Assocs. Inc., Assessment of the Economic and Social Characteristics of LIHTC Residents and Neighborhoods 4-24 (2000).

29. Cummings \& DiPasquale, supra note 9, at 268.

30. But see Kirk McClure, The Low-Income Housing Tax Credit as an Aid to Housing Finance: How Well Has It Worked?, 11 Housing PoL'y Debate 91, 97-98 (2000) (finding that developers have looked at operating costs and rewards instead of these minimum income requirements and that units tend to mostly be designated for moderate-income households). 
ies that examine LIHTC households due to an absence of data. Although the LIHTC program has existed since 1986, it was not until 2010 that Congress mandated that state housing agencies provide tenant data to the United States Department of Housing and Urban Development ("HUD"). ${ }^{31}$

In one of the few studies that examined the characteristics of LIHTC tenants, Buron et al. examined the social and economic characteristics of tenants in 39 LIHTC properties established between 1992 and 1994 in five metropolitan areas. ${ }^{32}$ Looking at the income of LIHTC tenants, the study found the properties serve primarily extremely and very-low-income households with approximately $40 \%$ of the households having extremely low incomes (below 30\% of the area median) and $34 \%$ having very low income (between $31-50 \%$ of the median). ${ }^{33}$ In addition to being very or extremely low-income, LIHTC residents tend to be working families who are members of a racial or ethnic minority. ${ }^{34}$ The United States General Accounting Office also collected data on LIHTC tenants from a randomly selected group of 423 projects established between 1992 and 1994 and found that the LIHTC properties had a majority of residents that were extremely low and very-low-income households. ${ }^{35}$ They also found that the majority of tax credit tenants are white $(53 \%)$ compared to $33 \%$ black. $^{36}$

More recently, Anne R. Williamson examined rent affordability among LIHTC residents. She analyzed tenant data for 30\% of LIHTC residents in Florida in 311 developments and found different results. She reported that only $14.1 \%$ of households had income below $30 \%$ of AMI, $43 \%$ had income between $30 \%$ and $50 \%$ of AMI, and a large share $(42.9 \%)$ had income greater than $50 \%$ of AMI. ${ }^{37}$ In another study, Katherine M. O'Regan and Keren M. Horn used tenant-level data from 18 states, representing almost $40 \%$ of all LIHTC units, to examine the incomes of tenants to determine if the program reaches those with extremely low incomes. ${ }^{38}$ They found that approximately $45 \%$ of tenants have extremely low incomes, and the overwhelming majority of these tenants also receive some form of rental assistance. Rent burdens are lower than that for renters with similar incomes nationally but generally higher than that presumed for housing programs of HUD. O'Regan and Horn found evidence of economically diverse

31. Katherine M. O'Regan \& Keren M. Horn, What Can We Learn About the Low-Income Housing Tax Credit Program by Looking at the Tenants?, 23 Housing Pol'y Debate 597, 598 (2013).

32. Buron ET AL., supra note 27, at 1-6 to 1-7.

33. Id. at 3-5 to 3-6.

34. Id. at 3-1 to 3-3.

35. U.S. Gen. Acct. Off., Tax Credits: Opportunities to Improve OverSight of the Low-Income Housing Program 37-38 (1997).

36. $I d$. at $42-43$.

37. Anne R. Williamson, Can They Afford the Rent? Resident Cost Burden in Low Income Housing Tax Credit Developments, 47 Urb. Aff. Rev. 775, 787-788 (2011). 38. O'Regan \& Horn, supra note 30. 
LIHTC developments, as well as evidence of LIHTC developments with high concentrations of households with extremely low incomes. ${ }^{39}$

\section{Recent Legal Developments Relevant to LiHTC Siting Decisions}

In 2015, the United States Supreme Court directly addressed the issue of low-income housing tax credits and residential racial segregation. In Texas Department of Housing \& Community Affairs v. Inclusive Communities Project, Inc., the plaintiffs argued that the Texas housing finance agency violated the federal Fair Housing Act ("FHA") by disproportionately allocating tax credits in a manner that furthered patterns of residential racial discrimination. ${ }^{40}$ Evidence presented at trial showed that $92.29 \%$ of LIHTC-financed units in Dallas were developed in census tracts with less than $50 \%$ of white residents. ${ }^{41}$ The plaintiffs brought the claim under a disparate impact theory of liability, under which plaintiffs need not show evidence of intentional discrimination but rather can prevail by proving that a challenged policy has a disproportionately negative impact based on race or national origin. ${ }^{42}$

While declining to decide the underlying merits of the case, the United States Supreme Court for the first time explicitly endorsed the disparate impact theory of liability under the FHA. ${ }^{43}$ The decision, which is binding on all United States lower courts, upheld the ability of plaintiffs to prevail in a lawsuit without showing evidence of intentional discrimination. Rather, evidence that a policy is causing a discriminatory effect may be sufficient to violate the FHA. The Supreme Court stated that plaintiffs must establish "robust" causality between the challenged policy and the disparate impact. ${ }^{44}$ The Court also endorsed HUD's interpretation of disparate impact liability under the FHA. ${ }^{45}$ HUD's interpretation provides that even if a defendant can show that its policy furthers a legitimate government interest, a plaintiff nonetheless can prevail if it can show that there is a less discriminatory alternative method of meeting the interest. ${ }^{46}$

While the Inclusive Communities litigation was pending, another significant legal development occurred related to LIHTC siting decisions and fair housing. HUD promulgated a new rule interpreting the "affirmatively furthering fair housing" ("AFFH") provisions of the

39. Id. at 598, 602-607.

40. 135 S. Ct. 2507 (2015).

41. Tex. Dep't of Hous. \& Cmty. Affairs v. Inclusive Cmtys. Project, Inc., 135 S. Ct. 2507, 2514 (2015).

42. Id. at 2514.

43. Id. at 2525 .

44. Id. at 2523 .

45. Id.

46. See 24 C.F.R. $\S 100$ (2018) (HUD regulation implementing the FHA's discriminatory effects standard). 
FHA. HUD has long interpreted these provisions as imposing obligations on communities that receive federal housing and community development assistance. HUD states that the AFFH requirement means:

taking meaningful actions, in addition to combating discrimination, that overcome patterns of segregation and foster inclusive communities free from barriers that restrict access to opportunity based on protected characteristics. Specifically, affirmatively furthering fair housing means taking meaningful actions that, taken together, address significant disparities in housing needs and in access to opportunity, replacing segregated living patterns with truly integrated and balanced living patterns, transforming racially and ethnically concentrated areas of poverty into areas of opportunity, and fostering and maintaining compliance with civil rights and fair housing laws. The duty to affirmatively further fair housing extends to all of a program participant's activities and programs relating to housing and urban development. ${ }^{47}$

Under the new rule, communities must engage in a new "assessment of fair housing" process, which requires communities to examine, among other things, whether the spatial locations of assisted housing indicate a disproportionately high share of units in Racially/Ethnically Concentrated Areas of Poverty ("R/E CAPs"). R/E CAPs are defined as census tracts where the non-Hispanic white population is less than $50 \%$ and the population living below poverty makes up over $40 \%$ of the total. Communities that fail to engage in the requisite analysis and planning are at risk of losing their federal housing and community development funding.

The Trump administration has taken steps to stop the AFFH process. HUD suspended until 2020 the requirement that communities analyze the level of racial and economic segregation and prepare plans to reverse these patterns. This action does not repeal the 2015 HUD rule; a repeal takes an act of Congress. However, it is within HUD's regulatory powers to delay enforcement of the rule. ${ }^{48}$ HUD has taken the additional step of no longer supporting the data and mapping tool that communities were supposed to use to prepare an AFFH plan, but fair housing advocates are challenging these steps in court. 49

The prior research indicates that the LIHTC program is failing to serve as a mechanism to either deconcentrate poverty or to affirmatively further fair housing. Regardless of the results of pending litiga-

47. 24 C.F.R. $§ 5.152$ (2018).

48. Emily Badger \& John Eligon, Trump Administration Postpones an Obama Fair-Housing Rule, N.Y. Times (Jan. 4, 2018), https://www.nytimes.com/2018/01/ 04/upshot/trump-delays-hud-fair-housing-obama-rule.html [https://perma.cc/3P7V-K RXD].

49. Ben Lane, HUD Kills Key Tool Used to Enforce Obama Fair Housing Rule, HousINGWIRE (May 18, 2018), https://www.housingwire.com/articles/43415-hud-killskey-tool-used-to-enforce-obama-fair-housing-rule [https://perma.cc/TG5A-65EJ]. 
tion, the Inclusive Communities case and the new AFFH rule, as well as the legal activity surrounding it, suggest that officials at state and local levels are entering a new era that will test their capacity to implement the LIHTC program with greater effectiveness. Such officials, working in concert with planners, would be wise to ensure that the locations of LIHTC developments demonstrate that low-income households served by the development are offered housing in highopportunity neighborhoods offering racially and economically integrated environments with access to good schools and gainful employment.

\section{Data AND Analysis}

\section{A. Data and Methods}

This research examines the entire portfolio of LIHTC developments in metropolitan areas of the United States to determine whether LIHTC units have been located in a manner that promotes poverty deconcentration and racial/ethnic integration. It does not examine non-metropolitan tracts because the focus is on neighborhood location. Low-income renter households in non-metropolitan areas have few options to improve their living environment by moving to another nearby neighborhood. The LIHTC data were obtained from HUD and joined with census tract data from the American Community Survey for 2011 to 2015. HUD identified R/E CAPS using Census 2010 data. To our knowledge, this is the first research to examine the locations of LIHTC developments on a national scale in terms of the distribution inside and outside of HUD's R/E CAPs.

\section{B. Analysis}

1. How Many R/E CAPS Exist and What Share of the Population and Rental Housing Stock Do They Contain?

R/E CAPs comprise only a small share of all tracts. Only $4.3 \%$ of metropolitan tracts meet the HUD definition. The population in general is indicating the lack of desirability of R/E CAPs by locating elsewhere. Only a smaller $3.2 \%$ of the total population live in R/E CAPs. As might be expected, a larger $(8.7 \%)$ share of the population living below poverty reside in R/E CAPS, despite the limited (5.5\%) share of rental housing. Thus, the non-poor population is avoiding these tracts. 
TABLE 1.

R/E CAPs, Population, Rental Housing and

Population Below Poverty

\begin{tabular}{llll}
\hline & & Population & \\
Count of & & Below & Rental \\
Tracts & Population & Poverty & Units \\
\hline
\end{tabular}

Non-R/E CAP

Tracts

Percent

R/E CAP Tracts

Percent

All Metropolitan

Tracts

$\begin{array}{rrrr}64,063 & 288,014,572 & 40,503,987 & 41,242,069 \\ 95.7 \% & 96.8 \% & 91.3 \% & 94.5 \% \\ & & & \\ 2,879 & 9,403,567 & 3,879,921 & 2,417,753 \\ 4.3 \% & 3.2 \% & 8.7 \% & 5.5 \%\end{array}$

$\begin{array}{rrrr}66,942 & 297,418,139 & 44,383,908 & 43,659,822 \\ 100.0 \% & 100.0 \% & 100.0 \% & 100.0 \%\end{array}$

2. How Many LIHTC Units Are There By Year Placed in Service? What Share Left the Program?

Neighborhood location is important to this study. Thus, the analysis is restricted to the approximately 2.43 million LIHTC units with census tract information, which is missing for about $7 \%$ of the total approximately 2.62 million LIHTC units produced by the program. Using the units with location information, the analysis is looking at the 2.13 million LIHTC units in 33,148 projects that are located in metropolitan tracts.

About 150,000 LIHTC units in metropolitan tracts have left the program. Almost all of those leaving the program were built in the early years of the program.

The LIHTC program produced more units and projects per year during the period prior to and during the housing bubble (1987-1999 and 2000-2007). Prior to 2008, the program developed about 1,300 projects and about 80,000 units annually in metropolitan areas. After the housing bubble collapsed, the program developed about 900 projects annually with about 67,000 units. 
TABLE 2.

Low-Income Housing Tax Credit Projects and

Units By Year Placed in Service in

Metropolitan Census Tracts

\begin{tabular}{|c|c|c|c|c|}
\hline & \multicolumn{3}{|c|}{ Year Placed in Service } & \multirow[t]{2}{*}{ Total } \\
\hline & 1987 to 1999 & 2000 to 2007 & 2008 to 2015 & \\
\hline \multicolumn{5}{|l|}{ LIHTC } \\
\hline \multirow[t]{2}{*}{ Projects } & 14,772 & 11,088 & 7,288 & 33,148 \\
\hline & $44.6 \%$ & $33.4 \%$ & $22.0 \%$ & $100.0 \%$ \\
\hline \multirow[t]{2}{*}{ LIHTC Units } & 705,172 & 888,669 & 539,760 & $2,133,601$ \\
\hline & $33.1 \%$ & $41.7 \%$ & $25.3 \%$ & $100.0 \%$ \\
\hline \multicolumn{5}{|l|}{ Units Left } \\
\hline \multirow[t]{2}{*}{ Program } & 140,459 & 8,460 & 2,107 & 151,026 \\
\hline & $93.0 \%$ & $5.6 \%$ & $1.4 \%$ & $100.0 \%$ \\
\hline
\end{tabular}

3. To What Extent Have LIHTC Developments Located in $\mathrm{R} / \mathrm{E}$ CAPs?

The LIHTC program is over represented in R/E CAPs, placing about $15 \%$ of its units in these tracts. The program placed a consistent share of projects in R/E CAPs over its existence. About $14 \%$ of all projects were placed in R/E CAPs during the three periods studied. The share of program units in R/E CAPs experienced some growth over time. The share grew from $13 \%$ in the early years to $16 \%$ in the post- bubble period. The program has placed a higher share of units in $\mathrm{R} / \mathrm{E}$ CAPs than would be expected either from the share of tracts that are R/E CAPs $(4 \%)$ or the share of the poor in R/E CAPs $(9 \%)$. The higher share of LIHTC units in R/E CAPs probably reflects the use of the LIHTC program as part of community and neighborhood revitalization plans.

Among LIHTC units leaving the program, a rising share were located in R/E CAPs. This rising share is probably due to LIHTC projects experiencing financial problems. All LIHTC developments developed within the last fifteen years remain under low-income occupancy agreements. Thus, those developments leaving the program during the last fifteen years are not leaving because they have completed this occupancy period but because of other problems. The incidence of these problems appears to be greater in R/E CAPSs. A higher share of units in R/E CAPs left the program in recent years $(39 \%)$ than the share of recently developed units in R/E CAPs $(16 \%)$. 
TABLE 3.

Low-Income Housing Tax Credit Units By Year

Placed in Service to R/E CAPs in

Metropolitan Census Tracts

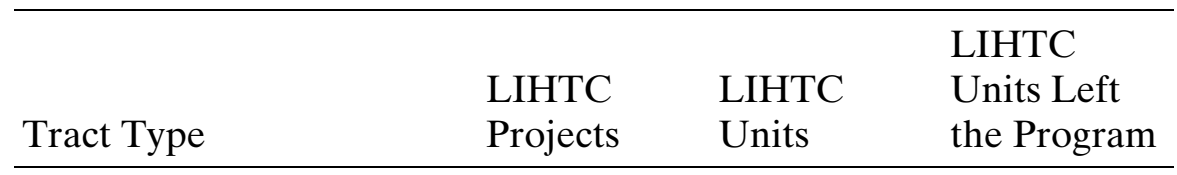

1987-1999

$\begin{array}{llll}\text { Non-R/E CAPs } & 85.6 \% & 86.6 \% & 85.3 \% \\ \text { R/E CAPs } & 14.4 \% & 13.4 \% & 14.7 \%\end{array}$

2000-2007

Non-R/E CAPs

$85.8 \%$

$85.5 \%$

$70.7 \%$

$\mathrm{R} / \mathrm{E}$ CAPs

$14.2 \%$

$14.5 \%$

$29.3 \%$

2008-2015

Non-R/E CAPs

$86.1 \%$

$83.7 \%$

$61.4 \%$

$\mathrm{R} / \mathrm{E}$ CAPs

$13.9 \%$

$16.3 \%$

$38.6 \%$

All Years

Non-R/E CAPs

$85.8 \%$

$85.4 \%$

$84.1 \%$

$\mathrm{R} / \mathrm{E}$ CAPs

$14.2 \%$

$14.6 \%$

$15.9 \%$

4. Where Are LIHTC Units Located By R/E CAPs and Racial/ Ethnic Composition of Tracts?

A note of caution is necessary. The data do not provide information on the race or ethnicity of the households who live in LIHTC units. The data only identify the racial and ethnic composition of the tracts where the units are located. It is possible, but unlikely, that the population in the LIHTC projects is very different from the surrounding neighborhood providing a vehicle for integration. Given this limitation built into the data, the analysis speaks only to the location of the LIHTC units and not to the racial or ethnic mixing between the populations in the LIHTC developments and the surrounding neighborhoods.

To examine the racial and ethnic composition of all metropolitan tracts, the tracts were divided into categories. Predominantly black tracts have a black population greater than $50 \%$. Similarly, predomi- 
nantly Hispanic tracts have a Hispanic population greater than $50 \%$. Predominantly white tracts are identified with a higher threshold. To be categorized as predominantly white, the non-Hispanic white population must be greater than $75 \%$. The higher threshold is because a lower threshold of $50 \%$ would categorize a tract as predominantly white when its black or Hispanic population could be as much as twice its share in the population total. Such tracts would probably be viewed as integrated. For this reason, predominantly white tracts are those with non-Hispanic whites comprising $75 \%$ or more of the population, and the remaining non-minority tracts are categorized as integrated.

About $44 \%$ of all tracts are predominantly white, but these tracts contain only $22 \%$ of LIHTC units. This percentage of units has been relatively stable over time; the program has not made any greater entry into these tracts. About $9 \%$ of tracts are predominantly black, but they also contain $22 \%$ of LIHTC units. Thus, the LIHTC program is concentrating units in black tracts. Again, this percentage of units has been stable over time. Similarly, $10 \%$ of tracts are predominantly Hispanic, but these tracts contain a higher $14 \%$ of LIHTC units. This is a lesser level of bias than found for black tracts, but still a bias is found toward minority concentration.

Integrated tracts are $37 \%$ of all tracts and contain a higher $42 \%$ of LIHTC units. It could be argued that the greatest contribution of the LIHTC program is its provision of moderately priced units in integrated settings. In integrated tracts, about 900,000 LIHTC units have been developed, which is a very large portion of the portfolio of LIHTC units. Of possible concern are the 70,000 LIHTC units (about $8 \%$ ) that are located in integrated tracts designated as R/E CAPs by HUD. These 70,000 units are probably viewed as part of a neighborhood revitalization plan, and they may be experiencing some success in that effort. The tract was designated a R/E CAP based on HUD's 2010 analysis, but these tracts have become integrated by the time of the 2015 analysis reported here. This suggests that the LIHTC program may be making a contribution toward promoting racial integration.

Despite this possible success, the bias toward location in minorityconcentrated tracts continues when looking at the R/E CAPs. Among $\mathrm{R} / \mathrm{E}$ CAPs, predominantly black tracts make up $48 \%$ of the total, but these tracts contain $55 \%$ of the LIHTC units in the R/E CAPs. 
TABle 4.

Low-Income Housing Tax Credit Units By Year Placed in Service to R/E CAPs and Tracts By Race and Ethnicity in Metropolitan Census Tracts

\begin{tabular}{llllll}
\hline & \multicolumn{3}{l}{ Year Placed in Service } & Total & Tracts \\
\cline { 2 - 5 } Tract Type & 1987 to & 2000 to & 2008 to & & \\
\hline
\end{tabular}

\section{Non-R/E CAP}

White greater than $75 \%$

$\begin{array}{rrrrr}178,266 & 172,754 & 113,724 & 464,744 & 29,535 \\ 29.2 \% & 22.7 \% & 25.2 \% & 25.5 \% & 46.1 \% \\ & & & & \\ 89,740 & 123,262 & 75,225 & 288,227 & 4,437 \\ 14.7 \% & 16.2 \% & 16.6 \% & 15.8 \% & 6.9 \% \\ & & & & \\ 71,643 & 105,224 & 60,706 & 237,573 & 5,729 \\ 11.7 \% & 13.8 \% & 13.4 \% & 13.0 \% & 8.9 \% \\ 270,736 & 358,583 & 202,189 & 831,508 & 24,362 \\ 44.4 \% & 47.2 \% & 44.7 \% & 45.6 \% & 38.0 \% \\ & & & & \\ 610,385 & 759,823 & 451,844 & 1,822,052 & 64,063 \\ 100 \% & 100 \% & 100 \% & 100 \% & 100 \%\end{array}$

\section{R/E CAP}

White greater than $75 \%$

$\begin{array}{lllll}0 & 0 & 0 & 0 & 0\end{array}$

Black greater than $50 \%$

$\begin{array}{rrrrr}52,115 & 71,771 & 47,449 & 171,335 & 1,389 \\ 55.0 \% & 55.7 \% & 54.0 \% & 55.0 \% & 48.3 \% \\ & & & & \\ 19,848 & 29,895 & 20,751 & 70,494 & 812 \\ 20.9 \% & 23.2 \% & 23.6 \% & 22.6 \% & 28.2 \% \\ 22,824 & 27,180 & 19,716 & 69,720 & 676 \\ 24.1 \% & 21.1 \% & 22.4 \% & 22.4 \% & 23.5 \% \\ & & & & \\ 94,787 & 128,846 & 87,916 & 311,549 & 2,877 \\ & & & & \\ 100 \% & 100 \% & 100 \% & 100 \% & 100 \%\end{array}$

Total in R/E CAP tracts

Hispanic greater than $50 \%$

Integrated

27

Black greater than

Hispanic greater

Total in non-R/E

CAP tracts

0 (n) 


\begin{tabular}{llllll}
\hline & \multicolumn{3}{l}{ Year Placed in Service } & Total & Tracts \\
\cline { 2 - 5 } Tract Type & 1987 to & 2000 to & 2008 to & \\
\hline
\end{tabular}

\begin{tabular}{lrrrrr} 
All Tracts & & & & & \\
White greater than & & & & & \\
$75 \%$ & 178,266 & 172,754 & 113,724 & 464,744 & 29,537 \\
& $25.3 \%$ & $19.4 \%$ & $21.1 \%$ & $21.8 \%$ & $44.1 \%$ \\
Black greater than & & & & & \\
$50 \%$ & 141,855 & 195,033 & 122,674 & 459,562 & 5,826 \\
& $20.1 \%$ & $21.9 \%$ & $22.7 \%$ & $21.5 \%$ & $8.7 \%$ \\
Hispanic greater & & & & & \\
than 50\% & 91,491 & 135,119 & 81,457 & 308,067 & 6,541 \\
& $13.0 \%$ & $15.2 \%$ & $15.1 \%$ & $14.4 \%$ & $9.8 \%$ \\
Integrated & 293,560 & 385,763 & 221,905 & 901,228 & 25,038 \\
& $41.6 \%$ & $43.4 \%$ & $41.1 \%$ & $42.2 \%$ & $37.4 \%$ \\
& & & & & \\
Total tracts & 705,172 & 888,669 & 539,760 & $2,133,601$ & 66,942 \\
& & & & & \\
& $100 \%$ & $100 \%$ & $100 \%$ & $100 \%$ & $100 \%$ \\
\hline
\end{tabular}

\section{What Can Be Done? What Should Be Done?}

For many years, it has been the policy of HUD to use housing programs to promote the deconcentration of poverty. ${ }^{50}$ HUD sees value in locating assisted households in neighborhoods offering high-opportunity neighborhoods. This recognition was the hypothesis that motivated the Moving to Opportunity program. ${ }^{51}$ HUD expects program administrators to help subsidized low-income households locate in such areas. ${ }^{52}$ Unfortunately, HUD does not provide clear guidance on what constitutes a high-opportunity area. ${ }^{53}$ Further, as a feature of the tax code, the LIHTC program is administered by the Internal Revenue Service rather than HUD. The fact that administration of

50. See, e.g., Jill Khadduri, Deconcentration: What Do We Mean? What Do We Want?, 5 CitysCAPE 69 70-73 (2001).

51. See Xavier de Souza Briggs, Susan J. Popkin \& John Goering, Moving to Opportunity: The Story of an American Experiment to Fight Ghetto Poverty (2010).

52. HUD Policy Changes to Improve Access to Low Poverty Neighborhoods, U.S. DeP'T of Hous. \& Urban Dev.: PD\&R Edge, https://www.huduser.gov/portal/pdr edge/pdr_edge_frm_asst_sec_061515.html [https://perma.cc/REB9-UQBU] (last visited July 21, 2019).

53. See generally Kirk McClure, The Prospects for Guiding Housing Choice Voucher Households to High-Opportunity Neighborhoods, 12 CITYSCAPE 101 (2010). 
assisted housing programs is split across two very different federal agencies, along with the fact that the primary oversight responsibility remains with states, no doubt contributes to the locational outcomes of the program. Some of the burden of guiding site selection decisions must be taken up by state and local planners. It is up to these planners to identify the high-opportunity neighborhoods where LIHTC developments should be located.

What is a high-opportunity neighborhood? There seems to be little agreement on what criteria define a high-opportunity neighborhood. Many criteria may contribute to defining it. ${ }^{54}$ There seems to be agreement that low levels of poverty should be a criterion but that other factors need to be included as well. ${ }^{55}$ As part of the AFFH process, HUD has released public access data at the census tract level that can be used to identify high-opportunity tracts. ${ }^{56}$ These data include indexes for poverty, labor force participation, transportation costs, school proficiency as well as other measures of tract opportunity level.

The HUD AFFH data have been used to build a composite index of tract opportunity level for all tracts in metropolitan areas. The index was constructed for each metropolitan tract by adding the percentage of the population living below poverty, the HUD transportation cost index, the school proficiency index, and the labor market engagement index. All tracts have been ordered by rank and categorized into quintiles with the top two quintiles defined as high-opportunity tracts and the bottom two quintiles categorized as low-opportunity tracts. Note that this is only one possible set of tract level measures that can be combined to form a composite index. Many other combinations were tested, and the overall results did not prove to be very sensitive to the factors included. Because these measures of neighborhood opportunity level are so highly correlated, different composite indexes tend to rank census tracts in a very similar order.

It is important to note that state and local planners may have access to more and better data for their jurisdiction. The HUD data are readily available and permits comparisons between jurisdictions across the country, but the data have flaws. For example, the HUD data do not provide an index on crime exposure. Escaping from high levels of crime and violence has been found to be a primary motivation for low-income households seeking to relocate into high-opportu-

54. Id. at 103-05, 107.

55. Alex Schwartz, Kirk McClure \& Lydia B. Taghvi, Vouchers and Neighborhood Distress: The Unrealized Potential for Families with Housing Choice Vouchers to Reside in Neighborhoods with Low Levels of Distress, 18 CITYSCAPE 207, 212-13 (2016).

56. U.S. Dep't of Hous. \& Urban Dev., AFFH Data and Mapping Tool, HUD ExCHANGE (Sept. 2017), https://www.hudexchange.info/resource/4867/affh-data-andmapping-tool/ [https://perma.cc/X9PQ-BALK]. 
nity neighborhoods. ${ }^{57}$ As local planners attempt to build their own definitions of high-opportunity neighborhoods, they may include locally available crime data. They should use the best data available including those known to accurately calibrate the desirability of neighborhoods in the jurisdiction.

Table 5 lists the counts of LIHTC units located in high-opportunity tracts (top 40\%) as well as low-opportunity tracts (bottom $40 \%$ ) by racial and ethnic category. By definition, $40 \%$ of the tracts in metropolitan areas of the nation are high-opportunity locations as determined by the composite index. Virtually all of the high-opportunity tracts are either predominantly white $(55 \%)$ or integrated $(41 \%)$. The number of high-opportunity minority-dominated tracts is miniscule (only 570 Hispanic and 431 black) among 26,335 total tracts. Thus, it is not presently possible to place LIHTC units in a significant number of high-opportunity tracts without fostering placement in predominantly white or racially or ethnically integrated areas.

The LIHTC program is making some entry into high-opportunity tracts. These tracts comprise $40 \%$ of all tracts, and these desirable tracts contain $21 \%$ of all LIHTC units. LIHTC units are under-represented in these tracts, but developers are able to enter these markets. State and local planners should help to push the AFFH process by defining desirable areas for LIHTC developments through identifying high-opportunity tracts. These tracts should offer locations with access to good schools, services, and employment prospects in a racially and ethnically integrated setting.

Unfortunately, the LIHTC program is not doing all that it should. For example, about $7 \%$ of all tracts are predominantly black, low-opportunity tracts, but these tracts contain a heavily disproportionate $18 \%$ of all LIHTC units. The integrated tracts in high-opportunity areas make up $16 \%$ of all tracts, but these tracts contain only $12 \%$ of the LIHTC units located in only $11 \%$ of the total tracts. Clearly, the LIHTC units are under-represented in the neighborhoods that both promote movement to high-opportunity neighborhoods and affirmatively further fair housing.

57. Tama Leventhal \& Jeanne Brooks-Gunn, Moving to Opportunity: An Experimental Study of Neighborhood Effects on Mental Health, 93 Ам. J. Pub. Health 1576, 1581 (2003). 
TABLE 5.

Low-Income Housing Tax Credit Units to Tracts By Racial/Ethnic Composition and Opportunity Level in Metropolitan Census Tracts

\begin{tabular}{llll}
\hline & & \multicolumn{2}{l}{ Count of Tracts } \\
\cline { 3 - 4 } Tract By Opportunity Level and & LIHTC & Tracts with & All \\
Racial/Ethnic Composition & Units & LIHTC & Metropolitan \\
& & Units & Tracts \\
\hline
\end{tabular}

High-opportunity tracts

\begin{tabular}{|c|c|c|c|}
\hline (top $40 \%$ of opportunity index) & 473,677 & 4,208 & 26,335 \\
\hline Percent in all tracts & $21 \%$ & $24 \%$ & $40 \%$ \\
\hline White greater than $75 \%$ & 191,881 & 2,225 & 14,482 \\
\hline Percent in all tracts & $8 \%$ & $13 \%$ & $22 \%$ \\
\hline Black greater than $50 \%$ & 6,827 & 52 & 431 \\
\hline Percent in all tracts & $0.3 \%$ & $0.3 \%$ & $0.7 \%$ \\
\hline Hispanic greater than $50 \%$ & 9,885 & 73 & 570 \\
\hline Percent in all tracts & $0.4 \%$ & $0.4 \%$ & $0.9 \%$ \\
\hline Integrated & 265,084 & 1,858 & 10,852 \\
\hline Percent in all tracts & $12 \%$ & $11 \%$ & $16 \%$ \\
\hline $\begin{array}{l}\text { Low-opportunity tracts } \\
\text { (bottom } 40 \% \text { of opportunity } \\
\text { index) }\end{array}$ & $1,369,463$ & 9,869 & 26,415 \\
\hline Percent in all tracts & $61 \%$ & $56 \%$ & $40 \%$ \\
\hline White greater than $75 \%$ & 176,426 & 2,313 & 4,612 \\
\hline Percent in all tracts & $8 \%$ & $13 \%$ & $7 \%$ \\
\hline Black greater than $50 \%$ & 413,125 & 2,394 & 4,451 \\
\hline Percent in all tracts & $18 \%$ & $14 \%$ & $7 \%$ \\
\hline Hispanic greater than $50 \%$ & 284,504 & 1,730 & 8,306 \\
\hline Percent in all tracts & $13 \%$ & $10 \%$ & $13 \%$ \\
\hline Integrated & 495,408 & 3,432 & 9,046 \\
\hline Percent in all tracts & $22 \%$ & $20 \%$ & $14 \%$ \\
\hline
\end{tabular}




\section{What Resources Are Available to Planners?}

Table 6 lists many possible indicators of neighborhood health that have appeared in the literature. State and local planners can obtain these data at the census tract level for use in defining an opportunity index that fits the needs of their individual jurisdictions. Poverty is one of the few that is generally accepted across nearly all published work. However, the thresholds to categorize a neighborhood as lowpoverty vary from $10 \%$ to $15 \%$ and could vary further depending upon local conditions. School quality is not easy to measure, but the percent of fourth grade students performing at grade level in math and reading on state tests has become an accepted indicator of school quality. HUD's index uses this approach. With the development of the Longitudinal Employer-Household Dynamics data from the United States Bureau of the Census, planners now have access to counts of the number of jobs in a tract, rather than the number of workers which is what was previously available from the Census. These data allow planners to assess the proximity of a location to jobs. Access to jobs is not just a function of proximity, it is also a function of access to transportation. HUD's transportation cost index attempts to estimate the costs associated with travel to work from various locations. Often, local planners will have local transit data that can improve upon these estimates of access to transportation. The FBI's Uniform Crime Reporting system ensures that crime data are already available at the local level, but comparison of these crime reports across jurisdictions can be misleading. However, many jurisdictions, especially large cities, make consistently counted crime data available at disaggregated levels such as census tracts. Where available, these crime data can be very valuable in assessing the desirability of neighborhoods.

Exposure to environmental hazards is another area where neighborhoods differ. The HUD environmental health hazard index uses information from the Environmental Protection Agency on air quality to assess the relative health threats across locations. Access to health care services is a matter of concern, especially for the poor, but no single database is readily available to assess this factor by location. However, as hospitals are increasingly engaged in preparing Community Health Needs Assessments, local measures of health care access are becoming available and can be used to assess neighborhood level access to health services. Home Mortgage Disclosure Act ("HMDA") data have been available to planners for some time but has rarely been used to develop indicators of neighborhood health. Publicly available HMDA data can be aggregated at the census tract level to assess the extent to which homebuyers are purchasing homes in a neighborhood or existing homeowners are reinvesting in fixing up their homes, both good measures of neighborhood condition. Finally, local planners will always know best which services are most valued in 
a local context. Usually, local tax assessor's data can facilitate determination of proximity of various neighborhoods to the services that are essential to a neighborhood's desirability. This is not an exhaustive list; other indicators of neighborhood health exist. Any combination of these neighborhood indicators can form an index that assesses whether a neighborhood is a high-opportunity neighborhood.

TABLE 6.

Neighborhood Indicators in Metropolitan

Census Tracts

\begin{tabular}{ll}
\hline Indicators & Source of Data \\
\hline Poverty & American Community Survey \\
School Proficiency & HUD AFFH Data \\
Labor Market Engagement & HUD AFFH Data \\
Transportation Cost Index & HUD AFFH Data \\
Crime & $\begin{array}{l}\text { FBI Uniform Crime Reports } \\
\text { or local reports }\end{array}$ \\
Environmental Threats & $\begin{array}{l}\text { HUD AFFH Data } \\
\text { or local reports }\end{array}$ \\
Health Care Access & Local data \\
Investor Confidence & Home Mortgage Disclosure Act \\
Access to Services & Local data \\
\hline
\end{tabular}

VIII. Conclusions And Policy Implications

This research examines whether developers have located LIHTC developments well. Do the locations promote poverty deconcentration and movement to high-opportunity neighborhoods? The answer is that the program has not performed especially well. The locations of LIHTC units tend to further establish patterns of poverty concentration. LIHTC developments tend to be located in tracts with already high levels of racial/ethnic segregation and poverty.

Do the locations of LIHTC units affirmatively further fair housing? The answer to this question is both yes and no. The negative response results from the disproportionately high placement of LIHTC units in 
predominantly black or Hispanic neighborhoods and the low placement in predominantly white tracts. This is compounded by the high incidence of LIHTC units in R/E CAPs. However, positive findings are gleaned from the fact that LIHTC units are making entry into integrated, high-opportunity tracts.

The implications of this research are that the program is capable of working well, but much more work needs to be done. State and local officials can and should take a role in guiding the locations of LIHTC developments. Working with planners, they should identify high-opportunity neighborhoods that promote racial and ethnic integration using the best available data. These data can be derived either from national sources, such as HUD or the American Community Survey, or from local sources that can better assess the desirability of neighborhoods using criteria not well measured by HUD or American Community Survey data.

In most states, competition for LIHTC resources is fierce. This enhances state and local officials' ability to foster LIHTC development in high-opportunity neighborhoods. Once planners have identified high-opportunity neighborhoods, they can use various methods to achieve placement of LIHTC developments in those neighborhoods. State officials have a very powerful tool in the QAP and can use selection preferences to encourage development in high-opportunity neighborhoods. For example, starting in 2018, California is incorporating a sophisticated methodology of "opportunity mapping" into its LIHTC allocation process.

Local planning tools will depend to some extent on how the state housing finance agency structures competition for the LIHTC, and the role they assign to local governments. In states where local government approval is required at the time of application, local officials can introduce a selection preference system based on points or other mechanisms that encourage developers to choose high-opportunity neighborhoods. In states where local government input into the LIHTC selection process is permitted, but not required, local officials can make it clear that they will be providing input to the state housing finance agency based upon neighborhood criteria. Finally, where local governments do not have a formally recognized role in the selection of LIHTC developments to be funded through the state housing finance agency, local planners can reach out to state agency planners and work towards the design of a system that includes local planning considerations.

Structural barriers may exist with respect to building LIHTC developments in high-opportunity neighborhoods. For example, higher land costs may make development less attractive to developers. Some states have experimented with innovative programs to address this challenge. For example, in Massachusetts, a new Donation Tax Credit ("DTC"), based on similar programs in Missouri and Illinois, provides 
a tax credit equal to $50 \%$ of the value of land donated to qualified nonprofits to be used for affordable housing. The program is intended to work in conjunction with the federal charitable deduction. Officials at the state level might advocate for experimentation with similar programs.

Another potential barrier to pushing LIHTC developments into high-opportunity neighborhoods may be local political opposition. Again, states are exploring innovative ways of ensuring that such opposition does not impede otherwise worthy affordable housing developments. For example, California recently enacted SB 35, prohibiting cities from discriminating against affordable housing projects that receive public assistance. The law also creates a streamlined approval process for proposed projects where cities have not hit their state-required affordable housing production targets. State officials could help develop and advocate for similar policies in other jurisdictions. These are of course only a few examples of strategies that might be employed.

TABLE 7.

Potential Barriers to Development in High-

OpPORTUNity NeighborhoOdS AND

Potential Strategies to Help

Address Them

\begin{tabular}{|c|c|c|}
\hline Barriers & Strategies & Examples \\
\hline $\begin{array}{l}\text { Current QAP } \\
\text { Scoring } \\
\text { Priorities }\end{array}$ & $\begin{array}{l}\text { Shift Scoring Criteria to } \\
\text { Prioritize Developments } \\
\text { Located in High- } \\
\text { Opportunity } \\
\text { Neighborhoods }\end{array}$ & $\begin{array}{l}\text { See California } \\
\text { Opportunity } \\
\text { Mapping } \\
\text { Methodology }\end{array}$ \\
\hline $\begin{array}{l}\text { Higher Land } \\
\text { Acquisition } \\
\text { Costs }\end{array}$ & Land Donation Tax Credits & $\begin{array}{l}\text { See Recently } \\
\text { Enacted } \\
\text { Massachusetts } \\
\text { Donation Tax Credit }\end{array}$ \\
\hline $\begin{array}{l}\text { Local Political } \\
\text { Opposition }\end{array}$ & $\begin{array}{l}\text { State-Level Streamlined } \\
\text { Approval Process }\end{array}$ & $\begin{array}{l}\text { See Recently } \\
\text { Enacted California } \\
\text { SB } 35\end{array}$ \\
\hline
\end{tabular}


